Special issue of the 3rd International Conference on Computational and Experimental Science and Engineering (ICCESEN 2016)

\title{
Evaluation of Uncertainty Contributions of Measurement Surface and Number of Microphone Positions in Determination of Sound Power Levels
}

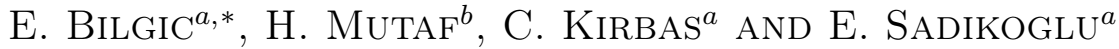 \\ ${ }^{a}$ TÜBİTAK Ulusal Metroloji Enstitüsü (UME), Gebze Kocaeli, Turkey \\ ${ }^{b}$ Gaziantep University, Department of Physics Engineering, Şehitkamil, Turkey
}

\begin{abstract}
Sound power level of a noise source is determined by means of sound pressure level or sound intensity level measurements performed in accordance to relevant ISO standards. The determination of sound power level according to ISO 3744, 3745 and 3746 standards is used for free field or for approximated free field conditions. Kinds of measurement surfaces, enveloping the noise source, number of microphones and their positions over the measurement surface are stated in the applied ISO standard. The effects of measurement surface and number of microphone positions on the determination of sound power level were investigated theoretically. As a measurement surface; hemisphere, parallelepiped rectangular box and cylindrical surfaces were selected. Key and additional microphone positions were taken into account in the calculations as well. Sound pressure levels of a commercially available reference sound source were measured in hemi-anechoic room using FFT with $4 \mathrm{~Hz}$ steps and also at $1 / 1,1 / 3,1 / 12$ and 1/24 octave bands for all surfaces defined in ISO 3744 and 3746 standards. Sound power level, directivity index and uncertainty contributions resulting from measurement surfaces and number of microphone positions were calculated by using data obtained in measurements. In this paper the theoretical and experimental results are presented.
\end{abstract}

DOI: 10.12693/APhysPolA.132.642

PACS/topics: 06.20.Dk, 06.20.fb

\section{Introduction}

There is lots of equipment, devices or machines, that radiate noise into the environment in which we live. In some cases the noise levels, that we are exposed to, are rated as harmful for hearing and/or disturbing for working comfort. Therefore levels of noise, emitted by those sources, must be measured and declared as the requirements of directives, e.g. The Machinery Directive 2006/42/EC, Energy Labeling Directive 2010/30/EU and Outdoor Noise Directive 2000/14/EC.

Sound power level is the preferred quantity for the energy labeling of noise sources. There are various methods, having different accuracy levels, in different acoustic fields. Generally preferred method is the method in which sound pressure level is measured over an enveloping surface, surrounding the noise source hypostatically, and then sound power level is calculated by using surface averaged sound pressure level and measurement surface area. These kinds of measurement methods are standardized in ISO 3745 [1] for free field, in ISO 3744 [2] and in ISO 3746 [3] for essentially free field.

Another method for determination of sound power level is the averaging of the sound pressure in reverberant environments, which are described in ISO 3741 [4] and ISO $3743[5,6]$ for diffuse and nearly diffuse field respectively. In case of sound intensity measurement,

*corresponding author; e-mail: eyup.bilgic@tubitak.gov.tr the methods used are standardized in ISO 9614-1, 9614-2 and 9614-3 [7-9]. Some author have used different algorithms for determination of sound power level of noise sources [10].

Investigations, related in particular to error and uncertainty analysis of the determination of sound power level of noise sources were performed and their results were published [11,12]. Recently, the results of European project "EMRP JRP SIB 56 SoundPwr-Realisation, dissemination and application of the unit of watt in airborne sound" were presented at Internosie 2016 Congress [13-15]. Although the measurement method used for determination of the sound power level is standardized, the results for the same noise source may be different for different methods. In all of these different methods, sound power level is determined with an uncertainty of several dB. Two of the major components of the uncertainty budgets, given in the relevant standards, are the measurement surface and the number of microphone positions.

In order to be able to compare the determined sound power level of a noise source, ISO 3744 and 3746 standards were selected. First the theoretical calculation of sound power level of an ideal, point noise source was made for parallelepiped rectangular box and cylindrical measurement surface in comparison to the spherical surface. Then the point noise source was translated by $1 \mathrm{~m}$ from the origin of coordinate system in horizontal plane, in order to simulate the directivity effect of the noise source on the sound power level. Later on, sound pressure level measurements of a commercially available reference sound source in hemi-anechoic room were 
performed using FFT and constant percentage bandwidth (CPB) analysis at $1 / 1,1 / 3,1 / 12$ and $1 / 24$ octave bands, for all surfaces defined in ISO 3744 and ISO 3746 standards.

\section{Determination of sound power level of a source}

Sound power level of a noise source is calculated from sound pressure levels using Eq. (1).

$$
L_{w}=L_{p}^{\prime}-K_{1}-K_{2}+10 \log _{10}\left(\frac{S}{S_{0}}\right),
$$

where, $L_{w}$ is sound power level, $\mathrm{dB}$ re $1 \mathrm{pW}, L_{p}^{\prime}$ is surface time-averaged sound pressure level, dB re $20 \mu \mathrm{Pa}, K_{1}$ is background noise correction, $\mathrm{dB}, K_{2}$ is environmental correction term, $\mathrm{dB}, S$ is measurement surface area, $\mathrm{m}^{2}$ and $S_{0}$ is reference measurement surface area, $1 \mathrm{~m}^{2}$.

In sound power level calculations using Eq. (1), the terms $K_{1}$ and $K_{2}$ were assumed to be zero for simplicity, because sound pressure level of the noise source is much higher than the background noise level and measurements are performed in hemi-anechoic room. While three different measurement surfaces are defined in ISO 3744 for sound pressure level measurements, the hemisphere, the parallel-piped rectangular box and the cylindrical surface, only the hemisphere and the parallel-piped rectangular box surfaces are used in accordance to ISO 3746. Selection criteria for the radius of hemisphere, measurement distance and dimensions of rectangular box, radius and height of cylindrical surface are given in ISO 3744 and ISO 3746 standards. Number of key microphone positions over the selected measurement surface and also the rules for additional microphone positions are expressed in related standards.

\subsection{Measurement surfaces and number of microphone positions}

Ten key microphone positions and ten additional microphone positions are recommended in ISO 3744 over hemispherical measurement surface. Here it is assumed that noise source is mounted or placed on the reflective floor. Locations of microphone positions are different for all noise sources and for broadband noise sources. If noise sources emit discrete tones, all noise source positions shall be used, if noise sources emit no audible discrete tones, broadband noise sources positions shall be preferred.

Four key microphone positions and four additional microphone positions shall be used in accordance to ISO 3746, over hemispherical measurement surface. Coordinates of the microphone positions are tabulated in ISO 3744 and ISO 3746.

Minimum number of the key microphone positions over parallel-piped rectangular box measurement surface depends on dimensions of the noise source, measurement distance and also on type of partial grids, dividing the measurement surface. Possible combinations are given in ISO 3744. For minimum source dimensions and rectangular partial areas, minimum number of microphones positions is nine and increases to 19 and to 29 with additional positions.

In case of selecting triangular partial areas, minimum number of microphone positions increases from 10 to 20 and to 40 with additional positions. The selection rules for number of microphone positions and the dimensions of the measurement surface for ISO 3746 are similar to those defined in ISO 3744 standard.

Minimum five of microphone positions is enough for simple and small size source. Cylindrical measurement surface is used only in ISO 3744, but not in ISO 3746 standard. Measurement microphones are distributed on lateral surface and top surfaces of cylinder. Contrary to the hemispherical and rectangular box surfaces, the positions of the microphones on cylindrical measurement surface are not at fix points. However they are positioned on circular paths with special diameters and height. Number of microphone positions and their coordinates are related to the dimensions of cylinder. Minimum number of microphone positions on the cylindrical surface is six. Four microphone positions are on the lateral surface and two microphone positions are on the top surface.

\subsection{Theoretical calculation}

In order to compare sound power level of a noise source, determined on the measurement surfaces defined in ISO 3744 and ISO 3746, an ideal point noise source with zero directivity indexes was assumed. Because sound pressure levels are equal at every point over the hemisphere, the sound pressure level is uniform. Hemispherical measurement surface with radius of $2 \mathrm{~m}$ was selected as reference surface for calculation. Surface timeaveraged sound pressure level of the point source over hemisphere with radius $r=2 \mathrm{~m}$ was taken as $L_{p}^{\prime}=85 \mathrm{~dB}$ re $20 \mu \mathrm{Pa}$. Dimensions of other surfaces were restricted to the sizes that just enclose the radius of hemisphere. Thus the length and width of rectangular box were $4 \mathrm{~m}$ and its height was $2 \mathrm{~m}$. The radius and the height of cylindrical surface were $2 \mathrm{~m}$.

The term $10 \log _{10}\left(S / S_{0}\right)$ in Eq. (1) for the hemispherical surface is calculated as $14.002 \mathrm{~dB}$ and hence sound power level is calculated as $L_{w}=99.002 \mathrm{~dB}$ re $1 \mathrm{pW}$ for hemisphere. Surface time-averaged sound pressure levels for parallel-piped rectangular box and cylindrical measurement surfaces are different than $L_{p}^{\prime}=85 \mathrm{~dB}$, because of asymmetry of the measurement positions. Therefore, sound pressure level at every microphone position and path must be calculated using equation given below:

$$
L_{p_{R i}}=L_{p}^{\prime}+20 \log \left(\frac{r}{R_{i}}\right),
$$

where $R_{i}$ is the magnitude of the vector from the center of coordinate system to microphone position on the measurement surface. Then surface time-averaged sound pressure level is calculated as energy average, using equation given below, for equal areas and unequal areas on measurement surface, respectively.

$$
L_{p}^{\prime}=10 \log \left(\frac{1}{N_{m}} \sum_{i=1}^{N_{m}} 10^{0.1 L_{p_{R i}}}\right) \text { and }
$$




$$
L_{p}^{\prime}=10 \log \left(\frac{1}{S} \sum_{i=1}^{N_{m}} S_{i} 10^{0.1 L_{p_{R i}}}\right),
$$

where $N_{m}$ is the number of microphone positions, $S$ is the total measurement surface area, $\mathrm{m}^{2}, S_{i}$ is partial measurement surface area, $\mathrm{m}^{2}$.

Directivity index is another important parameter for the determination of sound power level. In case of large sound pressure range over the measurement surface, to increase the number of microphone positions is the mandatory requirement of applied ISO standard, because this reduces the directivity effect on sound pressure level, averaged over the measurement surface. Contrary to the classification of ISO 3744, it is engineering; directivity indexes calculated for the microphone positions located in accordance to the ISO 3744 are higher than those calculated for the microphone positions located in accordance to the ISO 3746. One main reason is that four of all measurement distances from noise source to the microphone locations, defined in ISO 3746, are equal to each other, however some distances defined in ISO 3744 are different from each other. The minimum uncertainty contribution, caused by the limited number of microphone positions, is achieved with the hemispherical measurement surface.

TABLE I

Calculation results for all measurement surfaces and all numbers of microphone positions.

\begin{tabular}{|c|c|c|c|c|c|c|c|c|}
\hline ISO & $\begin{array}{c}\text { Type of } \\
\text { measurement surface }\end{array}$ & $\begin{array}{l}\text { Number of } \\
\text { microphone } \\
\text { positions }\end{array}$ & $\begin{array}{c}\text { Measurement } \\
\text { surface area } \\
{\left[\mathrm{m}^{2}\right]}\end{array}$ & $\begin{array}{c}\text { Surface term } \\
{[\mathrm{dB}]}\end{array}$ & $\begin{array}{c}\text { Sound power } \\
\text { level dB } \\
\text { re. } 1 \mathrm{pW}\end{array}$ & $\begin{array}{l}\text { Difference } \\
\qquad[\mathrm{dB}]\end{array}$ & $\begin{array}{l}u_{\text {mic }} \\
{[\mathrm{dB}]}\end{array}$ & $\begin{array}{l}\text { Range } \\
{[\mathrm{dB}]}\end{array}$ \\
\hline \multirow{11}{*}{3744} & Hemisphere & 10 & 25.13 & 14.00 & 99.00 & 0.00 & 0.00 & 0.00 \\
\hline & \multirow{3}{*}{$\begin{array}{l}\text { Parallel piped box } \\
\text { with rectangular grid }\end{array}$} & 9 & 48.00 & 16.81 & 99.70 & 0.70 & 0.71 & 4.77 \\
\hline & & 19 & 48.00 & 16.81 & 99.86 & 0.86 & 0.35 & 4.77 \\
\hline & & 29 & 48.00 & 16.81 & 99.91 & 0.91 & 0.24 & 4.77 \\
\hline & \multirow{3}{*}{$\begin{array}{l}\text { Parallel piped box } \\
\text { with triangular grid }\end{array}$} & 10 & 48.00 & 16.81 & 100.55 & 1.55 & 0.17 & 1.05 \\
\hline & & 20 & 48.00 & 16.81 & 100.55 & 1.55 & 0.12 & 1.05 \\
\hline & & 40 & 48.00 & 16.81 & 99.97 & 0.97 & 0.12 & 2.20 \\
\hline & \multirow[t]{2}{*}{ Cylinder, equal area } & 6 & 37.70 & 15.76 & 99.73 & 0.73 & 0.40 & 2.40 \\
\hline & & 150 & 37.70 & 15.76 & 99.71 & 0.71 & 0.08 & 2.99 \\
\hline & \multirow[t]{2}{*}{ Cylinder, unequal area } & 6 & 37.70 & 15.76 & 99.59 & 0.59 & 0.40 & - \\
\hline & & 150 & 37.70 & 15.76 & 99.54 & 0.54 & 0.08 & - \\
\hline \multirow{2}{*}{3746} & Hemisphere & 4 & 25.13 & 14.00 & 99.00 & 0.00 & 0.00 & 0.00 \\
\hline & Parallel piped box & 5 & 48.00 & 16.81 & 101.06 & 2.05 & 0.19 & 0.97 \\
\hline
\end{tabular}

- Not calculated

TABLE II

Calculation results for all measurement surfaces and all numbers of microphone positions for shifted point source.

\begin{tabular}{|c|c|c|c|c|c|c|c|c|}
\hline ISO & $\begin{array}{c}\text { Type of } \\
\text { measurement surface }\end{array}$ & $\begin{array}{l}\text { Number of } \\
\text { microphone } \\
\text { positions }\end{array}$ & $\begin{array}{c}\text { Measurement } \\
\text { surface area } \\
{\left[\mathrm{m}^{2}\right]}\end{array}$ & $\begin{array}{l}\text { Surface term } \\
{[\mathrm{dB}]}\end{array}$ & $\begin{array}{c}\text { Sound power } \\
\text { level } \\
{[\mathrm{dB} \text { re. } 1 \mathrm{pW}]}\end{array}$ & $\begin{array}{l}\text { Difference } \\
{[\mathrm{dB}]}\end{array}$ & $\begin{array}{l}u_{\text {mic }} \\
{[\mathrm{dB}]}\end{array}$ & $\begin{array}{c}\text { Range } \\
{[\mathrm{dB}]}\end{array}$ \\
\hline \multirow{12}{*}{3744} & \multirow{2}{*}{ Hemisphere all sources } & 10 & 25.13 & 14.00 & 99.47 & 0.47 & 0.79 & 6.38 \\
\hline & & 20 & 25.13 & 14.00 & 99.69 & 0.68 & 0.58 & 7.95 \\
\hline & \multirow{2}{*}{ Hemisphere broadband } & 10 & 25.13 & 14.00 & 99.25 & 0.24 & 0.77 & 8.01 \\
\hline & & 20 & 25.13 & 14.00 & 99.47 & 0.47 & 0.57 & 9.31 \\
\hline & \multirow{3}{*}{$\begin{array}{c}\text { Parallel piped box } \\
\text { with rectangular grid }\end{array}$} & 9 & 48.00 & 16.81 & 100.13 & 1.12 & 0.86 & 9.29 \\
\hline & & 19 & 48.00 & 16.81 & 100.21 & 1.21 & 0.55 & 9.29 \\
\hline & & 29 & 48.00 & 16.81 & 100.28 & 1.28 & 0.43 & 9.29 \\
\hline & \multirow{3}{*}{$\begin{array}{l}\text { parallel piped box } \\
\text { with triangular grid }\end{array}$} & 10 & 48.00 & 16.81 & 100.91 & 1.91 & 0.75 & 7.74 \\
\hline & & 20 & 48.00 & 16.81 & 100.91 & 1.91 & 0.52 & 7.74 \\
\hline & & 40 & 48.00 & 16.81 & 100.40 & 1.40 & 0.36 & 9.07 \\
\hline & Cylinder, equal area & 24 & 37.70 & 15.76 & 100.23 & 1.22 & 0.51 & 6.02 \\
\hline & Cylinder, unequal area & 24 & 37.70 & 15.76 & 100.16 & 1.16 & 0.51 & 10.55 \\
\hline \multirow{3}{*}{3746} & \multirow{2}{*}{ Hemisphere, broadband } & 4 & 25.13 & 14.00 & 99.79 & 0.79 & 1.62 & 6.80 \\
\hline & & 8 & 25.13 & 14.00 & 99.30 & 0.30 & 0.89 & 7.80 \\
\hline & Parallel piped box & 5 & 48.00 & 16.81 & 101.39 & 2.38 & 1.14 & 6.99 \\
\hline
\end{tabular}


Uncertainty contributions of the measurement surface and number of microphone positions were calculated using expressions defined in Annex H of ISO 3744. The range for measurement distance in calculations was assumed to be $\Delta r=0.05 \mathrm{~m}$. Results of the calculations for all types of measurement surfaces and number of microphone positions are given in Table I. $u_{\text {mic }}$ is uncertainty contribution term due to the number of microphone positions. The term "Difference" in Table I is the difference between sound power levels in comparison to those obtained for hemispherical measurement surface. The range in $\mathrm{dB}$ for sound power level is the difference of maximum and minimum apparent directivity index for one measurement surface. In order to simulate typical asymmetric noise source in comparison to the measurement surface, the point source was shifted $1 \mathrm{~m}$ from the center of coordinate system along one of the axes in the horizontal plane, along $x$ axis, for example. Sound power levels were calculated for all types of surfaces and possible number of microphone positions. Results are presented in Table II.

\subsection{Measurements performed in hemi-anechoic room}

Determination of sound power level of a sound source was carried out for a commercially available reference sound source, Brüel \& Kjaer (B\&K) Type 4204, in hemi-anechoic room in TÜBİTAK UME. B\&K PULSE Type $3560 \mathrm{D}$ multi channel analyzer system and $1 / 2^{\prime \prime}$ condenser microphones G.R.A.S. Type 40AF and B\&K Type 4191 and Type 4133 were used in measurements. Measurement chain composed of microphone, preamplifier, cable and analyzer was checked before and after the measurement series by using B\&K Type 4231 Sound Calibrator.

TABLE III

Types of measurement surfaces, dimensions and number of microphone positions used in measurements.

\begin{tabular}{c|c|c|c|c}
\hline \hline ISO & $\begin{array}{c}\text { Type of } \\
\text { measurement } \\
\text { surface }\end{array}$ & $\begin{array}{c}\text { Dimensions } \\
{[\mathrm{m}]}\end{array}$ & $\begin{array}{c}\text { Surface } \\
\text { area } \\
{\left[\mathrm{m}^{2}\right]}\end{array}$ & $\begin{array}{c}\text { Number } \\
\text { of micro- } \\
\text { phone } \\
\text { positions }\end{array}$ \\
\hline 3744 & $\begin{array}{c}\text { Hemisphere } \\
\text { Parallel piped } \\
\text { rectangular box } \\
\text { Cylinder }\end{array}$ & $\begin{array}{c}r=1.5 \mathrm{~m} \\
\mathrm{~m} \times 3 \mathrm{~m} \times 1.5 \mathrm{~m}\end{array}$ & $\begin{array}{c}14.14 \\
27.00\end{array}$ & 10 \\
\hline $\begin{array}{c}\text { Hemisphere } \\
\text { Parallel piped } \\
\text { rectangular box }\end{array}$ & $3 \mathrm{~m} \times 3 \mathrm{~m} \times 1.5 \mathrm{~m}$ & 37.70 & 6 \\
\hline
\end{tabular}

Sound pressure level measurements in hemi-anechoic room were performed using FFT and $\mathrm{CPB}$ analysis at $1 / 1,1 / 3,1 / 12$ and $1 / 24$ octave bands for all surface types defined in ISO 3744 and ISO 3746 standards. Measurement parameters are given in Table III. Calculated sound power levels, their comparison and uncertainty contribution, resulted from the measurement surface, $u_{\text {surf }}$ are presented in Tables IV and V and in Figs. 1-10.

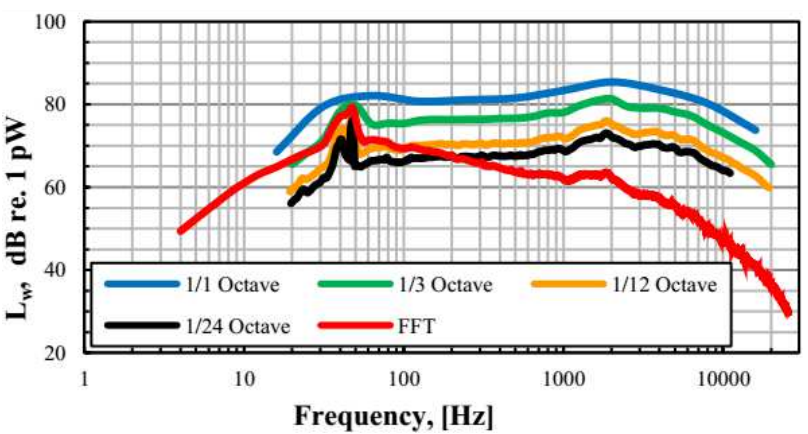

Fig. 1. Sound power level for ISO 3744 over hemisphere at positions for broadband noise source.

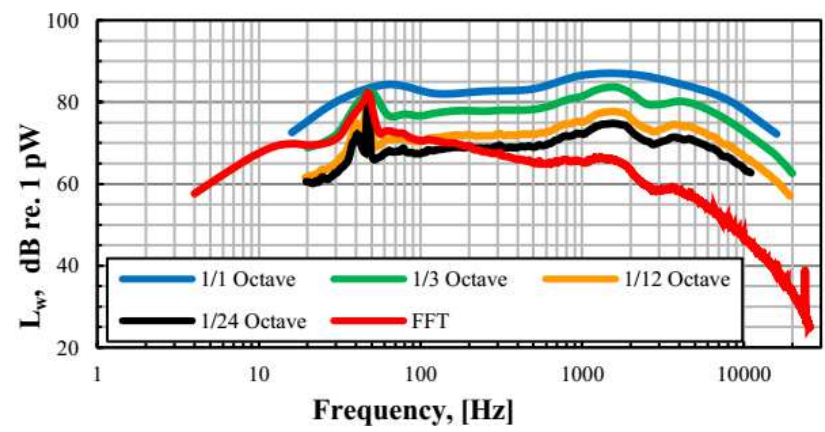

Fig. 2. Sound power level for ISO 3744 over cylindrical surface.

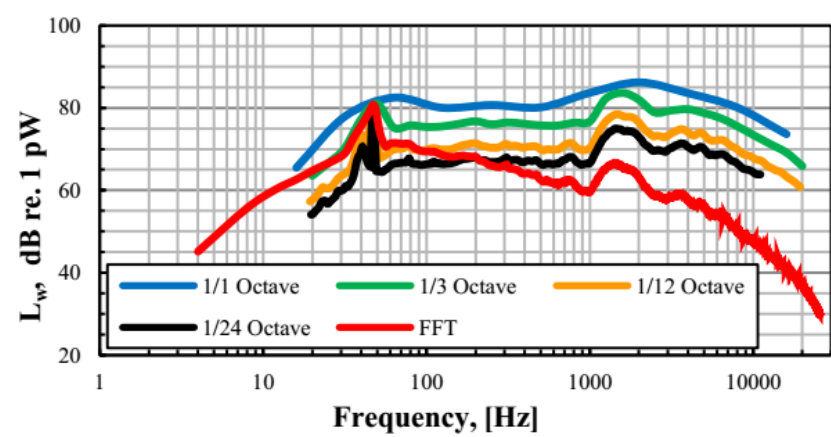

Fig. 3. Sound power level for ISO 3744 over parallelepiped rectangular box.

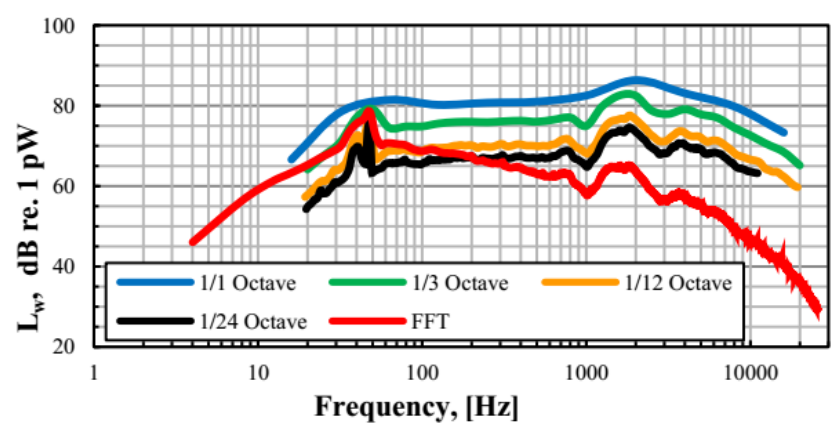

Fig. 4. Sound power level for ISO 3746 over hemisphere.

Range factors due to the measurement surface type are given in Table VI. A comparison between uncertainty contribution of number of microphone positions and surface type is made in Table VII and also in Figs. 11-14. 
Total sound power levels, A and linear frequency weighted.

TABLE IV

\begin{tabular}{|c|c|c|c|c|c|c|c|c|c|c|}
\hline \multirow{3}{*}{$\begin{array}{l}\text { Frequency } \\
\text { resolution }\end{array}$} & \multicolumn{6}{|c|}{ ISO 3744} & \multicolumn{4}{|c|}{ ISO 3746} \\
\hline & \multicolumn{2}{|c|}{ Hemisphere } & \multicolumn{2}{|c|}{$\begin{array}{l}\text { Parallel piped } \\
\text { rectangular box }\end{array}$} & \multicolumn{2}{|c|}{ Cylinder } & \multicolumn{2}{|c|}{ Hemisphere } & \multicolumn{2}{|c|}{$\begin{array}{l}\text { Parallel piped } \\
\text { rectangular box }\end{array}$} \\
\hline & $\mathrm{A}$ & Lin. & $\mathrm{A}$ & Lin. & $\mathrm{A}$ & Lin. & $\mathrm{A}$ & Lin. & $\mathrm{A}$ & Lin. \\
\hline $1 / 1$ & 90.54 & 91.65 & 90.88 & 91.76 & 2.22 & 93.37 & 90.61 & 91.47 & 92.70 & 93.55 \\
\hline $1 / 3$ octave & 90.57 & 91.94 & 91.38 & 92.42 & 92.28 & 93.64 & 90.64 & 91.71 & 92.74 & 93.77 \\
\hline 1/12 octave & 90.60 & 91.94 & 91.86 & 92.86 & 92.29 & 93.60 & 90.67 & 91.71 & 93.22 & 94.22 \\
\hline $1 / 24$ octave & 90.57 & 91.87 & 91.36 & 92.34 & 92.29 & 93.61 & 90.65 & 91.65 & 92.72 & 93.69 \\
\hline FFT & 92.29 & 93.68 & 93.08 & 94.13 & 93.98 & 95.37 & 92.35 & 93.43 & 94.44 & 95.49 \\
\hline
\end{tabular}

TABLE V

Uncertainty contribution due to the limited number of microphone positions and measurement surfaces.

\begin{tabular}{|c|c|c|c|c|c|c|c|c|c|c|}
\hline \multirow{3}{*}{ ISO } & \multirow{3}{*}{$\begin{array}{c}\text { Type of } \\
\text { measurement } \\
\text { surface }\end{array}$} & \multirow{3}{*}{$\begin{array}{l}\text { Frequency } \\
\text { weighting }\end{array}$} & \multirow{3}{*}{$\begin{array}{c}\text { Number of } \\
\text { microphone } \\
\text { positions }\end{array}$} & \multicolumn{5}{|c|}{ Band } & \multirow{3}{*}{$\begin{array}{c}\text { Surface } \\
\text { area } \\
{\left[\mathrm{m}^{2}\right]}\end{array}$} & \multirow{3}{*}{$\begin{array}{l}u_{\text {surf }} \\
{[\mathrm{dB}]}\end{array}$} \\
\hline & & & & $1 / 1$ & $1 / 3$ & $1 / 12$ & $1 / 24$ & FFT & & \\
\hline & & & & \multicolumn{5}{|c|}{$u_{\text {mic }}[\mathrm{dB}]$} & & \\
\hline \multirow{6}{*}{3744} & \multirow{2}{*}{ Hemisphere } & $\mathrm{A}$ & \multirow{2}{*}{10} & 0.30 & 0.30 & 0.31 & 0.29 & 0.30 & \multirow{2}{*}{14.14} & \multirow{2}{*}{0.17} \\
\hline & & Lin. & & 0.45 & 0.45 & 0.45 & 0.45 & 0.45 & & \\
\hline & \multirow{2}{*}{ Parallel piped rectangular box } & $\mathrm{A}$ & \multirow{2}{*}{9} & 0.71 & 0.71 & 0.71 & 0.71 & 0.71 & \multirow{2}{*}{27.00} & \multirow{2}{*}{0.11} \\
\hline & & Lin. & & 0.72 & 0.73 & 0.72 & 0.72 & 0.72 & & \\
\hline & \multirow{2}{*}{ Cylinder } & $\mathrm{A}$ & \multirow{2}{*}{6} & 0.83 & 0.83 & 0.82 & 0.80 & 0.81 & \multirow{2}{*}{37.70} & \multirow{2}{*}{0.13} \\
\hline & & Lin. & & 1.02 & 1.02 & 1.01 & 1.01 & 1.01 & & \\
\hline \multirow{4}{*}{3746} & \multirow{2}{*}{ Hemisphere } & $\mathrm{A}$ & \multirow{2}{*}{4} & 0.40 & 0.41 & 0.41 & 0.37 & 0.39 & \multirow{2}{*}{14.14} & \multirow{2}{*}{0.17} \\
\hline & & Lin. & & 0.67 & 0.68 & 0.68 & 0.67 & 0.68 & & \\
\hline & \multirow{2}{*}{ Parallel piped rectangular box } & $\mathrm{A}$ & \multirow[b]{2}{*}{5} & 0.19 & 0.20 & 0.20 & 0.17 & 0.18 & \multirow{2}{*}{27.00} & \multirow{2}{*}{0.11} \\
\hline & & Lin. & & 0.37 & 0.37 & 0.37 & 0.37 & 0.37 & & \\
\hline
\end{tabular}

Range in $\mathrm{dB}$, calculated from measured sound pressure levels.

TABLE VI

\begin{tabular}{|c|c|c|c|c|c|c|c|c|c|c|}
\hline \multirow{3}{*}{$\begin{array}{l}\text { Frequency } \\
\text { resolution }\end{array}$} & \multicolumn{6}{|c|}{ ISO 3744} & \multicolumn{4}{|c|}{ ISO 3746} \\
\hline & \multicolumn{2}{|c|}{$\begin{array}{l}\text { Hemisphere } \\
\text { (for } 9 \text { mic.) }\end{array}$} & \multicolumn{2}{|c|}{$\begin{array}{l}\text { Parallel piped } \\
\text { rectangular box } \\
\text { (for } 5 \text { mic.) }\end{array}$} & \multicolumn{2}{|c|}{$\begin{array}{l}\text { Cylinder } \\
\text { (for } 6 \text { mic.) }\end{array}$} & \multicolumn{2}{|c|}{$\begin{array}{l}\text { Hemisphere } \\
\text { (for } 4 \text { mic.) }\end{array}$} & \multicolumn{2}{|c|}{$\begin{array}{l}\text { Parallel piped } \\
\text { rectangular box } \\
\text { (for } 5 \text { mic.) }\end{array}$} \\
\hline & $\bar{A}$ & Lin. & $\bar{A}$ & Lin. & $\bar{A}$ & Lin. & $\bar{A}$ & Lin. & $\bar{A}$ & Lin. \\
\hline $1 / 1$ octave & 3.28 & 4.85 & 4.55 & 1.13 & 5.07 & 6.49 & 1.66 & 2.77 & 4.63 & 1.93 \\
\hline $1 / 3$ octave & 3.28 & 4.85 & 4.54 & 1.13 & 5.09 & 6.45 & 1.68 & 2.78 & 4.65 & 1.94 \\
\hline $1 / 12$ octave & 3.31 & 4.87 & 4.54 & 1.13 & 5.03 & 6.43 & 1.71 & 2.79 & 4.64 & 1.95 \\
\hline $1 / 24$ octave & 3.25 & 4.81 & 4.49 & 0.98 & 4.88 & 6.49 & 1.58 & 2.73 & 4.65 & 1.93 \\
\hline FFT & 3.24 & 4.89 & 4.48 & 1.01 & 4.95 & 6.45 & 1.64 & 2.74 & 4.67 & 1.93 \\
\hline
\end{tabular}

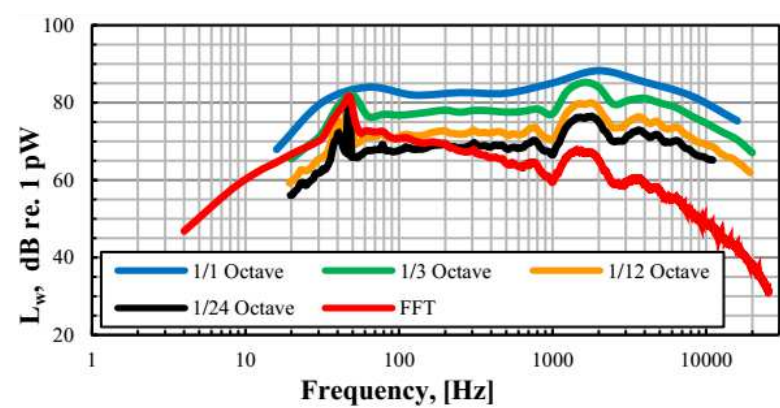

Fig. 5. Sound power level for ISO 3746 over parallelepiped rectangular box.

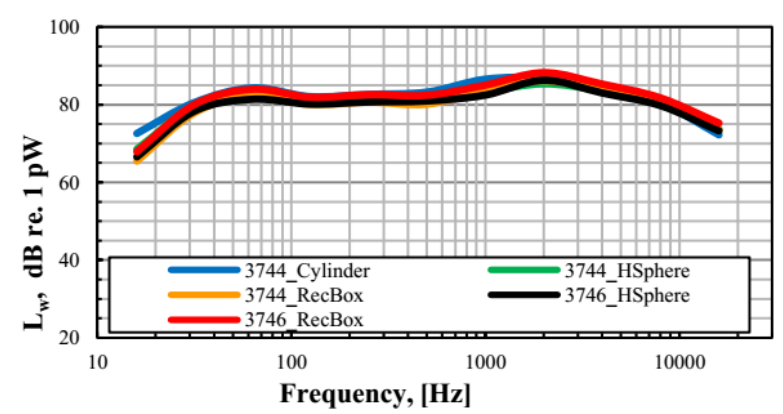

Fig. 6. Sound power level at $1 / 1$ octave bands, ISO 3744 and 3746 . 


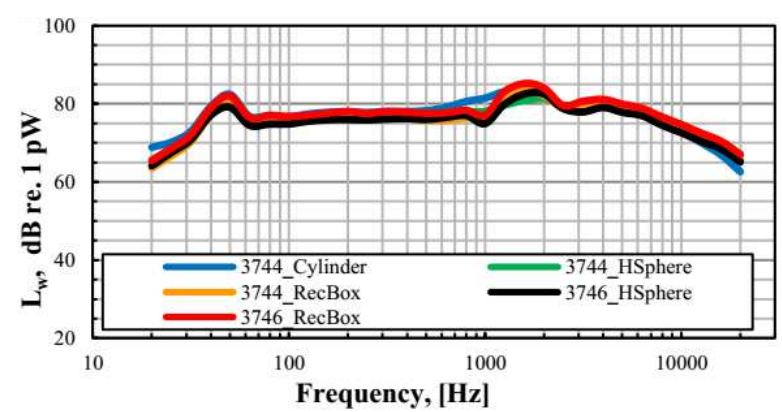

Fig. 7. Sound power level at $1 / 3$ octave bands, ISO 3744 and 3746.

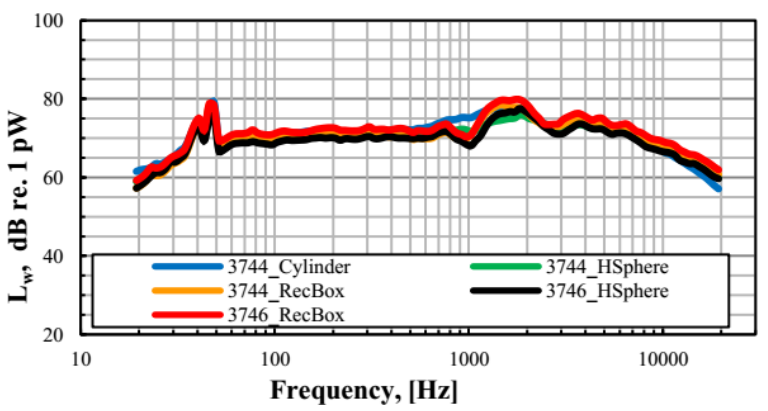

Fig. 8. Sound power level at $1 / 12$ octave bands, ISO 3744 and 3746.

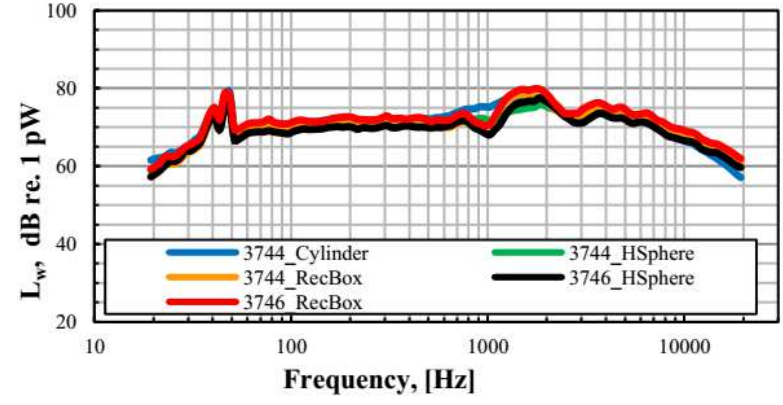

Fig. 9. Sound power level at $1 / 24$ octave bands, ISO 3744 and 3746.

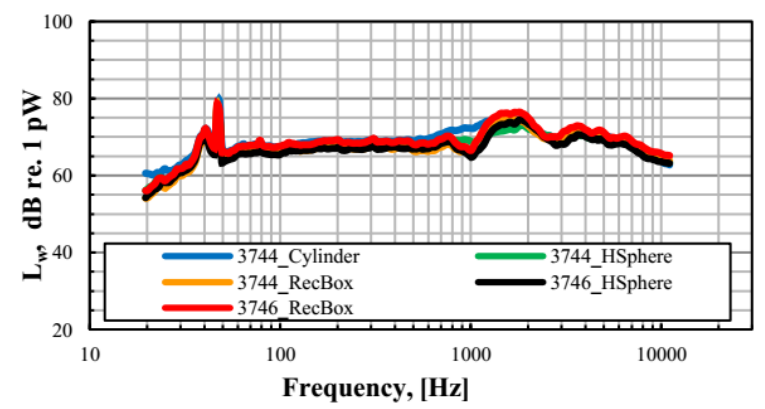

Fig. 10. Sound power level at FFT bands, ISO 3744 and 3746 .

TABLE VII

Comparison of uncertainty contributions, calculated theoretically and obtained from practical measurements.

\begin{tabular}{|c|c|c|c|c|c|c|c|}
\hline \multirow[b]{2}{*}{ ISO } & \multirow[b]{2}{*}{$\begin{array}{c}\text { Type of } \\
\text { measurement } \\
\text { surface }\end{array}$} & \multirow[b]{2}{*}{$\begin{array}{l}\text { Number of } \\
\text { microphone } \\
\text { positions }\end{array}$} & \multicolumn{2}{|c|}{ Theoretical calculation } & \multicolumn{3}{|c|}{ Practical measurement } \\
\hline & & & $\begin{array}{c}\text { Measurement } \\
\text { surface area } \\
{\left[\mathrm{m}^{2}\right]}\end{array}$ & $\begin{array}{l}u_{\text {mic }} \\
{[\mathrm{dB}]}\end{array}$ & $\begin{array}{c}\text { Measurement } \\
\text { surface area } \\
{\left[\mathrm{m}^{2}\right]}\end{array}$ & Weighting & $\begin{array}{l}u_{\text {mic }} \\
{[\mathrm{dB}]}\end{array}$ \\
\hline \multirow{6}{*}{3744} & Hemisphere & 10 & 25.13 & 0.00 & 14.14 & $\mathrm{~A}$ & 0.30 \\
\hline & & & & & & Lin. & 0.45 \\
\hline & Parallel piped rectangular & 9 & 48.00 & 0.71 & 2700 & $\mathrm{~A}$ & 0.71 \\
\hline & & 9 & & & 27.00 & Lin. & 0.73 \\
\hline & Cylinder & 6 & 37.70 & 0.40 & 3770 & $\mathrm{~A}$ & 0.83 \\
\hline & & & & & & Lin. & 1.02 \\
\hline \multirow{4}{*}{3746} & Hemisnhere & 4 & 2513 & 000 & 1414 & $\mathrm{~A}$ & 0.41 \\
\hline & nemispnere & 4 & 20.13 & 0.00 & 14.14 & Lin. & 0.68 \\
\hline & Parallel piped rectangular & 5 & 48.00 & 0.19 & 27.00 & A & 0.20 \\
\hline & & & & & & Lin. & 0.37 \\
\hline
\end{tabular}

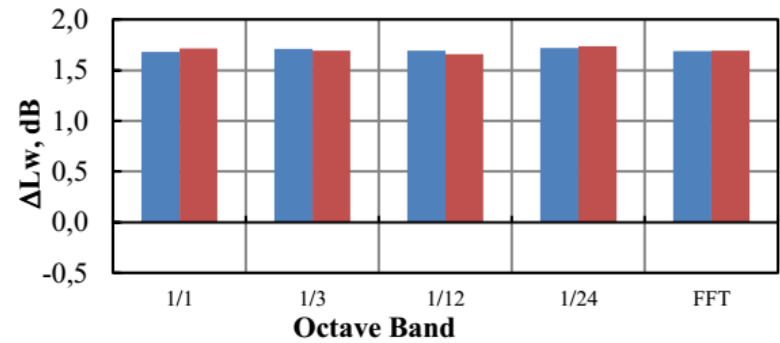

Fig. 11. Sound power level difference, $\Delta L_{w}$, determined over cylindrical and hemispherical surface for ISO 3744. Blue bars - A weighted, red bars - linear.

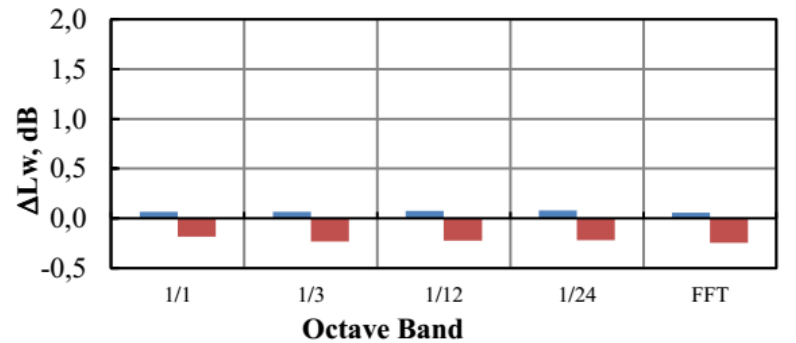

Fig. 12. Sound power level difference, $\Delta L_{w}$, determined over hemispherical surface for ISO 3746 and ISO 3744. Blue bars - A weighted, red bars - linear. 


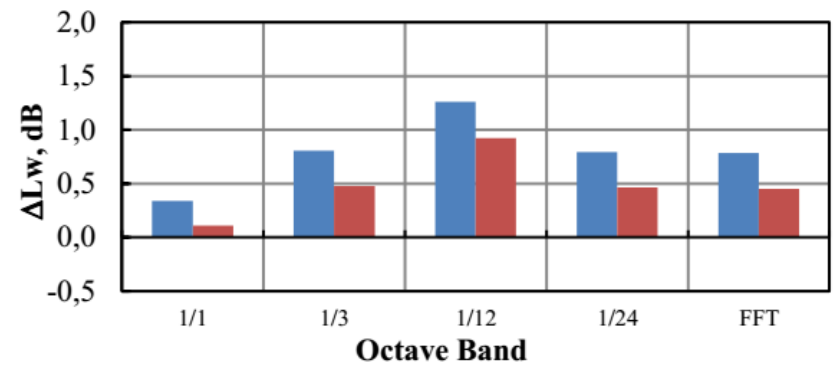

Fig. 13. Sound power level difference, $\Delta L_{w}$, determined over rectangular box and hemispherical surface for ISO 3744. Blue bars - A weighted, red bars - linear.

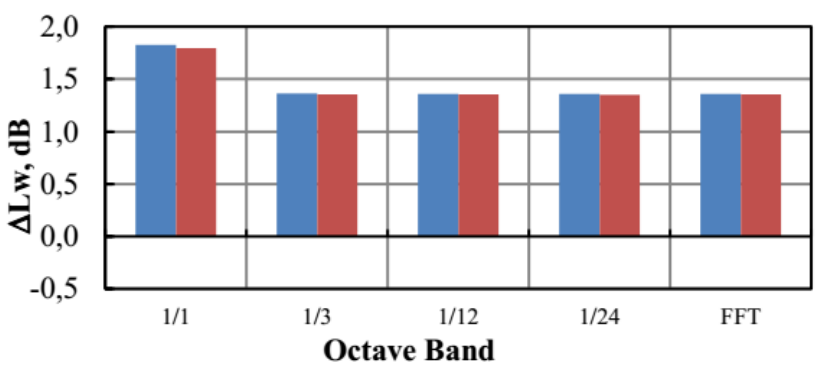

Fig. 14. Sound power level difference, $\Delta L_{w}$, determined over rectangular box surface for ISO 3746 and ISO 3744. Blue bars - A weighted, red bars - linear.

\subsection{Discussion}

Sound power level of a reference sound source was determined in accordance to ISO 3744 and ISO 3746 standards. Uncertainty contributions, resulting from measurement surface and number of microphone positions, presented in Table $\mathrm{V}$, were calculated for various octave bands and measurement surfaces on which the actual measurement was performed.

The results presented in Figs. 11-14 are used to compare the determined sound power levels, as energy labeling is performed by means of A-weighted sound power levels. Closest sound power levels were obtained over the hemispherical measurement surfaces, in accordance to ISO 3744 and ISO 3746, for the dedicated reference sound source. These are followed by sound power levels, obtained over the hemisphere and over the parallel-piped rectangular box, in accordance to ISO 3744. Generally, the biggest difference in sound power levels was obtained over the cylindrical and hemispherical surfaces, in accordance to ISO 3744. It can be concluded that hemispherical measurement surface shall be preferred in case of no practical restriction on selection of measurement surface, even though uncertainty contribution of this surface is slightly higher.

Uncertainty contributions for all types of measurement surfaces vary between $0.11 \mathrm{~dB}$ and $0.17 \mathrm{~dB}$. Uncertainty contributions of number of microphone positions for all types of measurement surfaces vary between $0.30 \mathrm{~dB}$ and $1.00 \mathrm{~dB}$ and are bigger in comparison to those of measurement surface contributions, as it is evident from values presented in Table V.
The range is an objective parameter of number of key microphone positions. If the range is smaller than the number of microphone positions for selected measurement surface, it is assumed that the number of microphone positions is large enough and fulfills the requirement of related ISO 3744 or 3746 standard. In this study the number of key microphone positions is smaller than the range only for cylindrical measurement surface and it is necessary to make measurements at additional microphone positions, as it can be seen from Table VI.

Table VII gives information on the uncertainty contribution of number of microphone positions, obtained theoretically and experimentally. The values are close to each other for the case of point source and for the reference source used in measurement, due to thir symmetry.

\section{Conclusions}

Uncertainty contributions of measurement surface, number of microphone positions and the apparent directivity index were calculated theoretically in accordance to ISO 3744 and ISO 3746 standards. Sound power levels of a sound source, quantified as a reference source, were determined from the measurements over different types of measurement surfaces using different number of microphones locations. Uncertainty values given in tables are calculated from measurements and are not much different from those given in ISO 3744 and ISO 3746. These values can be used in case when no data is available for an appropriate measurement surface and number of microphone positions.

\section{References}

[1] ISO 3745, Acoustics - Determination of sound power levels and sound energy levels of noise sources using sound pressure - Precision methods for anechoic rooms and hemi-anechoic rooms, International Organization for Standardization, Geneva 2012.

[2] ISO 3744, Acoustics - Determination of sound power levels and sound energy levels of noise sources using sound pressure - Engineering methods for an essentially free field over a reflecting plane, International Organization for Standardization, Geneva 2010.

[3] ISO 3746, Acoustics - Determination of sound power levels and sound energy levels of noise sources using sound pressure - Survey method using an enveloping measurement surface over a reflecting plane, International Organization for Standardization, Geneva 2010

[4] ISO 3741, Acoustics - Determination of sound power levels and sound energy levels of noise sources using sound pressure - Precision method for reverberation test room, International Organization for Standardization, Geneva 2010.

[5] ISO 3743-1, Acoustics - Determination of sound power levels and sound energy levels of noise sources using sound pressure - Engineering methods for small movable source in reverberant fields - Part 1: Comparison method for a hard walled test room, International Organization for Standardization, Geneva 2010. 
[6] ISO 3743-2, Acoustics - Determination of sound power levels of noise sources using sound pressure - Engineering methods for small movable source in reverberant fields - Part 2: Methods for a special reverberation test rooms, International Organization for Standardization, Geneva 1994.

[7] ISO 9614-1, Acoustics - Determination of sound power levels of noise sources using sound intensity Part 1: Measurement at discrete points, International Organization for Standardization, Geneva 1993.

[8] ISO 9614-2, Acoustics - Determination of sound power levels of noise sources using sound intensity Part 2: Measurement by scanning, International Organization for Standardization, Geneva 1996.

[9] ISO 9614-3, Acoustics - Determination of sound power levels of noise sources using sound intensity Part 3: Precision method for measurement by scanning, International Organization for Standardization, Geneva 2002
[10] Sungho Mun, Zong Woo Geem, Int. J. Industrial Ergonomics 39, 366 (2009).

[11] G. Hübner, J. Acoustical Soc. Am. 54, 967 (1973).

[12] R.P.B. da Costa-Felix, Measurement 39, 169 (2006).

[13] C. Kirbas, H. Andersson, C. Guglielmone, V. Wittstock, E. Bilgic, in: INTER-NOISE 2016, 45th Int. Congress and Exposition on Noise Control Engineering, 2016, p. 6737.

[14] K. Voelkel, V. Wittstock, in: INTER-NOISE 2016, 45th Int. Congress and Exposition on Noise Control Engineering, 2016, p. 6803.

[15] H. Andersson, V. Wittstock, in: INTER-NOISE 2016, 45th Int. Congress and Exposition on Noise Control Engineering, 2016, p. 6783. 